\title{
Loss of CUL4A expression is underlying cisplatin hypersensitivity in colorectal carcinoma cells with acquired trabectedin resistance
}

B Englinger ${ }^{1}$, M Mair ${ }^{1}$, W Miklos ${ }^{1}$, C Pirker ${ }^{1}$, T Mohr $^{1}$, S van Schoonhoven ${ }^{1}$, D Lötsch ${ }^{1}$, W Körner ${ }^{2}$, F Ferk ${ }^{1}$, S Knasmüller ${ }^{1}$, P Heffeter ${ }^{1,3}$, B K Keppler ${ }^{3,4}$, M Grusch ${ }^{1}$ and W Berger ${ }^{\star}, 1,3$

${ }^{1}$ Institute of Cancer Research and Comprehensive Cancer Center, Department of Medicine I, Medical University of Vienna, Borschkegasse 8a, A-1090 Vienna, Austria; ${ }^{2}$ Department of Environmental Geosciences, University of Vienna, Althanstraße 14, A-1090 Vienna, Austria; ${ }^{3}$ Research Platform 'Translational Cancer Therapy Research', University of Vienna and Medical University of Vienna, Waehringer Str. 42, A-1090 Vienna, Austria and ${ }^{4}$ Institute of Inorganic Chemistry, University of Vienna, Waehringer Str. 42, A-1090 Vienna, Austria

Background: Colorectal carcinoma (CRC) is the third most common cancer worldwide. Platinum-based anticancer compounds still constitute one mainstay of systemic CRC treatment despite limitations due to adverse effects and resistance development. Trabectedin has shown promising antitumor effects in CRC, however, again resistance development may occur. In this study, we aimed to develop strategies to circumvent or even exploit acquired trabectedin resistance in novel CRC treatment regimens.

Methods: Human HCT116 CRC cells were selected for acquired trabectedin resistance in vitro and characterised by cell biological as well as bioinformatic approaches. In vivo xenograft experiments were conducted.

Results: Selection of HCT116 cells for trabectedin resistance resulted in p53-independent hypersensitivity of the selected subline against cisplatin. Bioinformatic analyses of mRNA microarray data suggested deregulation of nucleotide excision repair and particularly loss of the ubiquitin ligase CUL4A in trabectedin-selected cells. Indeed, transient knockdown of CUL4A sensitised parental HCT116 cells towards cisplatin. Trabectedin selected but not parental HCT116 xenografts were significantly responsive towards cisplatin treatment.

Conclusions: Trabectedin selection-mediated CUL4A loss generates an Achilles heel in CRC cancer cells enabling effective cisplatin treatment. Hence, inclusion of trabectedin in cisplatin-containing cancer treatment regimens might cause profound synergism based on reciprocal resistance prevention.

Trabectedin (Yondelis, ecteinascidin 743) is a marine alkaloid originally derived from the sea squirt Ecteinascidia turbinata (Ganjoo and Patel, 2009; Vincenzi et al, 2010). The unique mechanism of action of trabectedin is distinct from that of other DNA-targeting anticancer agents. It binds to the $\mathrm{N} 2$ position of guanines in the minor groove of GC-rich regions, bending the
DNA helix towards the major groove (D'Incalci and Galmarini, 2010). In addition to forming covalent interactions with DNA, hence causing helix distortions and DNA damage, it also protrudes from the minor groove, where it interferes with various DNAbinding proteins. By this, trabectedin inhibits interaction of important transcription factors such as E2F, SRF or NF-Y with

*Correspondence: Professor W Berger; E-mail: walter.berger@meduniwien.ac.at

Revised 5 December 2016; accepted 15 December 2016; published online 17 January 2017

(c) 2017 Cancer Research UK. All rights reserved 0007-0920/17 
the respective binding sites at target gene promoters (Bonfanti et al, 1999). Another important function of trabectedin is based on its interference with nucleotide excision repair (NER) proteins such as $\mathrm{XPG}$, leading to the formation of cytotoxic ternary protein-DNA complexes. These complexes are thought to inhibit efficient recruitment of further repair factors, resulting in transcriptionand replication-coupled DNA double strand breaks and apoptosis induction (Larsen et al, 2016). This illustrates that functional NER is crucial for the action of trabectedin.

Nucleotide excision repair (NER) is a DNA repair mechanism that eliminates a wide range of structurally unrelated DNA lesions, including, amongst others, UV light-induced pyrimidine dimers, bulky adducts, and intrastrand crosslinks caused by chemotherapeutic agents such as cisplatin (Marteijn et al, 2014). This repair mechanism comprises the recognition of helix distortions by Xeroderma pigmentosum C (XPC) in conjunction with the auxiliary factors DNA damage-binding proteins DDB1 and DDB2 that associate with the cullin 4a (CUL4A)-containing E3 ubiquitin ligase complex CRL. Activation of the CRL complex leads to ubiquitylation of several key target proteins such as XPC itself to initiate removal of the DNA lesion. Defects in the NER pathway are associated with a variety of disorders such as xeroderma pigmentosum, resulting in predisposition to $\mathrm{UV}$-induced skin cancer but also in increased sensitivity towards alkylating agents and platinum drugs (Marteijn et al, 2014). Interestingly, this is in contrast to trabectedin, which is generally considered to be inactive in a NER-deficient background (Zewail-Foote et al, 2001; Herrero et al, 2006; Colmegna et al, 2014).

In the course of the last decades, remarkable activities have been described for trabectedin in various cancer types (Larsen et al, 2016). This has paved the way for clinical approval of trabectedin for patients with advanced soft tissue sarcoma who have failed or who are not eligible for first-line treatment with ifosfamide and anthracyclines as well as for combination with pegylated liposomal doxorubicin in therapy-refractory, platinum-sensitive ovarian cancer (Monk et al, 2010; Demetri et al, 2016; Moriceau et al, 2016). Besides these, there is also evidence for trabectedin efficacy in other cancer types such as meningioma or colorectal carcinoma (CRC; Paz-Ares et al, 2007; Preusser et al, 2012).

Colorectal carcinoma (CRC) is the third most commonly diagnosed cancer worldwide (Torre et al, 2015). In the last decades, the molecular pathogenesis of CRC has been elucidated in great detail, which has resulted in the identification of numerous mechanisms promoting tumorigenesis. Despite this, success in the search for molecular therapy targets and predictive biomarkers has been limited. To date, targeted therapies for treatment of CRC include the small molecule multi-kinase inhibitor regorafenib as well as monoclonal antibodies targeting vascular endothelial growth factor A (VEGF-A; bevacizumab) and epidermal growth factor receptor (cetuximab; Cohen et al, 2007; Lieberman, 2012; Li et al, 2015). However, also in the case of targeted agents, clinical benefit is often moderate and relapse occurs regularly (Stintzing, 2014). For these reasons, the use of chemotherapeutic agents such as oxaliplatin and irinotecan still constitutes the standard treatment for CRC and the mortality of this disease remains high at $\sim 33 \%$ in developed countries (Torre et al, 2015). Therefore, it is crucial that new therapeutic strategies are developed to improve the outcome of patients suffering from this disease. In preclinical studies, trabectedin has been described to exert strong cytotoxicity in CRC cell lines either as single agent or in combination with other anticancer compounds. However, also development of acquired resistance has been described (Takebayashi et al, 2001a; Stevens et al, 2008; Larsen et al, 2016).

Here we aimed to understand factors underlying unresponsiveness of CRC cells towards trabectedin and, further, to develop strategies to deal with or even exploit these mechanisms therapeutically. Therefore, we selected HCT116 human CRC cells with a p53 wild-type and knock-out (KO) background for resistance against trabectedin. Acquired HCT116 cell unresponsiveness towards trabectedin resulted in p53-independent and stable hypersensitivity against the platinum compounds cisplatin and carboplatin in vitro. Additionally, it resulted in cisplatin responsiveness of the respective xenografts in vivo. Hence combination regimens comprising cisplatin and trabectedin might exert synergistic and durable responses based on reciprocal resistance blockade.

\section{MATERIALS AND METHODS}

Cell culture. The human CRC cell lines HCT116 and its p53 - / counterpart HCT116-p53KO were kindly provided by Dr Vogelstein from John Hopkins University, Baltimore. HCT116 and HCT116-p53KO cells were cultured in McCoy's medium (Sigma, St. Louis, MO, USA) supplemented with $10 \%$ foetal calf serum (FCS, $\mathrm{PAA}, \mathrm{Linz}$, Austria) and $2 \mathrm{mM}$ glutamine (Sigma) at $37^{\circ} \mathrm{C}$ and $5 \%$ $\mathrm{CO}_{2}$. The human CRC cell lines DLD-1 and SW480 were obtained from American Type Culture Collection (Manassas, VA, USA) and cultured in RPMI-1640 supplemented with 10\% FCS. Cells were authenticated by array comparative genomic hybridisation (aCGH) and regularly checked for Mycoplasma contamination (Mycoplasma Stain kit, Sigma).

Drugs and chemicals. Trabectedin was obtained from Pharmamar (Madrid, Spain). TRAIL was purchased from Life Technologies (Carlsbad, CA, USA), Z-VAD-FMK from Enzo Life Sciences (Lausen, Switzerland). Cisplatin, carboplatin, oxaliplatin and novobiocin were purchased from Sigma.

Selection of HCT116 for acquired trabectedin resistance. The trabectedin-resistant subline HCT116/Y1 and its p53-/counterpart HCT116-p53KO/Y1 were generated by in vitro exposure to the drug. Cells were exposed to $100 \mathrm{~nm}$ trabectedin for $24 \mathrm{~h}$ twice weekly for several months. Revertant cell lines of both, HCT116/Y1 and HCT116-p53KO/Y1 cells, were generated by removal of trabectedin selection pressure for 6 months and were termed HCT116/Y1R and HCT116-p53KO/Y1R, respectively. Resistance levels were constantly monitored by cell viability assay.

Cell viability assay. To determine cell viability in response to drug exposure, $3 \times 10^{3}$ cells were seeded in 96-well plates and allowed to adhere for $24 \mathrm{~h}$. Cells were exposed to drugs or UV irradiated. After $72 \mathrm{~h}$, cell survival was determined by the 3-(4,5-dimethylthiazol-2-yl)-2,5-diphenyltetrazolium bromide (MTT)-based colorimetric vitality assay (EZ4U, Biomedica, Vienna, Austria) following the manufacturer's instructions. Dose-response curves were generated by GraphPad Prism software (San Diego, CA, USA). $\mathrm{IC}_{50}$ values were calculated expressing drug concentrations resulting in a $50 \%$ reduction of viable cell number in comparison to untreated controls.

Determination of DNA platination levels by inductively coupled plasma mass spectrometry. HCT116 and HCT116/Y1 cells $\left(3 \times 10^{5}\right)$ were seeded in six-well plates and exposed to $10 \mu \mathrm{M}$ or $25 \mu \mathrm{M}$ cisplatin at $37^{\circ} \mathrm{C}$ for 4 and $24 \mathrm{~h}$. DNA was isolated and DNA platination levels were determined by ICP-MS using an Elan 6100 (PerkinElmerSciex Instruments, Boston, MA, USA) as previousely described (Heffeter et al, 2010). Results are expressed as platinum amount per milligram of DNA. Data were analysed using GraphPad Prism software.

Modified alkaline comet assay (single-cell gel electrophoresis assay). To assess the levels of cisplatin-induced DNA crosslinking, DNA migration from nuclei of cells treated with increasing concentrations of cisplatin was studied using the modified alkaline comet assay (Tice et al, 2000; Zheng et al, 2005). Cells $\left(5 \times 10^{5}\right)$ 
were seeded in six-well plates and allowed to adhere for $24 \mathrm{~h}$. Cells were treated with the indicated concentrations of cisplatin for $1 \mathrm{~h}$, followed by an $8 \mathrm{~h}$ recovery phase in drug-free medium, allowing for cisplatin DNA interstrand crosslinks to form. Then, cells were exposed to $50 \mu \mathrm{M} \mathrm{H}_{2} \mathrm{O}_{2}$ for $1 \mathrm{~h}$ to induce constant numbers of random DNA strand breaks. Sample preparation and single-cell gel electrophoresis assay (SCGE) were performed with some modifications as previously described (Heffeter et al, 2009). Cell pellets were re-suspended in LMPA (0.5\%, Gibco, Paisley, UK) and transferred to slides pre-coated with NMPA (1.0\%, Gibco, Paisley, UK). Lysis ( $100 \mathrm{~mm}$ EDTA, $2.5 \mathrm{~m}$ sodium chloride and $10 \mathrm{mM}$ Trizma base, with freshly added $1 \%$ Triton X-100 and 10\% DMSO, $\mathrm{pH}$ 10.0) was carried out for at least $60 \mathrm{~min}$ at $4{ }^{\circ} \mathrm{C}$. After $30 \mathrm{~min}$ unwinding under alkaline conditions $(\mathrm{pH}>13)$, electrophoresis was carried out for $30 \mathrm{~min}\left(300 \mathrm{~mA}, 1.0 \mathrm{~V} \mathrm{~cm}^{-1}\right.$, at $\left.4^{\circ} \mathrm{C}\right)$ and neutralisation was performed twice for $8 \mathrm{~min}$. Air-dried slides were stained with ethidium bromide $\left(20 \mu \mathrm{g} \mathrm{ml}^{-1}\right)$. The percentage of DNA in the tails was measured by use of a computer aided image analysis system (Comet IV, Perceptive Instruments Ltd., Burry St. Edmunds, UK) under a fluorescence microscope (Nikon EFD-3, Tokyo, Japan) using 25-fold magnification. For each experimental point, three slides were prepared from each sample and 50 nuclei were evaluated from each slide. Statistical analyses were performed using GraphPad Prism software.

Confocal laser-scanning immunofluorescence microscopy. Cells $\left(5 \times 10^{4}\right)$ were seeded in eight-well chamber slides (BD Falcon, Franklin Lakes, NJ, USA) and allowed to adhere for $24 \mathrm{~h}$. Following $24 \mathrm{~h}$ cisplatin treatment, cells were fixed with ice-cold methanol/ acetone for $10 \mathrm{~min}$ and blocked with phosphate-buffered saline (PBS) containing 20\% FCS for $1 \mathrm{~h}$. Fixed cells were incubated with rabbit anti-phospho-H2AX antibody (Ser139, Cell Signaling Technology, Danvers, MA, USA) diluted 1:100 in PBS with 1\% FCS for $1 \mathrm{~h}$ at room temperature. After washing, cells were incubated with the goat anti-rabbit secondary antibody (Sigma) for $1 \mathrm{~h}$, conjugated with fluorescein isothiocyanate, diluted 1:1000 in PBS containing 1\% FCS. Nuclei were counterstained with $4^{\prime}, 6$ diamidino-2-phenylindole (DAPI) before mounting. Images were acquired on a LSM700 confocal laser scanning microscope (Zeiss, Jena, Germany) using a $\times 40$ immersion oil lens and Zen2010 software (Zeiss).

Western blot analysis. Protein extracts were prepared from total cell lysates and separated by sodium dodecyl sulphatepolyacrylamide gel electrophoresis (SDS-PAGE). Proteins were blotted onto polyvinylidene difluoride membranes (PVDF, Thermo Fisher Scientific, Waltham, MA, USA). The p53 antibody was purchased from Thermo Fisher Scientific. Antibodies against CUL4A, phosphoH2AX (Ser139), p21 and Bax were obtained from Cell Signaling Technology. 3 -actin (AC-15) was obtained from Sigma. The anti-HA antibody (3F10) was purchased from Roche (Basel, Switzerland). Horseradish peroxidase (HRP)-conjugated secondary antibodies were obtained from Santa Cruz Biotech (Dallas, TX, USA) and were used as 1:10 000 working dilutions.

Cell cycle analysis. Cells $\left(5 \times 10^{5}\right)$ were incubated in six-well plates and treated with different concentrations of cisplatin. After $48 \mathrm{~h}$, cells were collected and fixed with ice-cold 70\% ethanol. Cells were treated with RNase $\left(0.2 \mathrm{mg} \mathrm{ml}^{-1}\right.$, Sigma $)$ and DNA was stained using propidium iodide (PI, $0.01 \mathrm{mg} \mathrm{ml}^{-1}$, Sigma). Cell cycle distribution was determined by flow cytometry using FACS Calibur (Becton Dickinson, Palo Alto, CA, USA). Resulting DNA histograms were analysed using FlowJo software (Ashland, OR, USA).

Annexin V/propidium iodide staining and FACS analysis. Cells were treated for $24 \mathrm{~h}$ with the indicated cisplatin concentrations. To determine early apoptosis (Annexin V, BD Biosciences) and cell death (propidium iodide; PI) induction, cells were trypsinized, stained with APC-labelled Annexin V or PI and subjected to FACS analysis (FACS Calibur). The extent of apoptosis/cell death induction was analysed by FlowJo software.

Array comparative genomic hybridisation. Indirect aCGH was performed on $4 \times 44 \mathrm{~K}$ oligonucleotide-based microarrays (Agilent, Santa Clara, CA, USA) as previously described (Mathieu et al, 2012). Genome-wide relative gene doses of HCT116/Y1 cells were compared with those of the parental HCT116 cell line. DNA labelling and hybridisation was performed according to the manufacturer's instructions.

Whole-genome gene expression array. Transcriptional profiles of cells were determined performing a $4 \times 44 \mathrm{~K}$ whole genome oligonucleotide gene expression array (Agilent) as described previously (Laszlo et al, 2015). Data were analysed by GeneSpring software, filtering signalling intensity values according to sufficient (raw expression values $>20$ ) and significant differences in expression (as determined by unpaired $t$-test-Benjamini-Hochberg correction, $P$-value cutoff: 0.05$)$. In parallel, the whole dataset was subjected to gene set enrichment analysis (GSEA) and normalised in $\mathrm{R}$ software by the Robust Multi-array Average normalisation approach (http://www.broadinstitute.org/ gsea/msigdb/index.jsp).

siRNA knockdown of CUL4A. Cells $\left(5 \times 10^{5}\right)$ were transfected with $50 \mathrm{~nm}$ of CUL4A siRNA (Dharmacon, Lafayette, LA, USA) or an equimolar concentration of scrambled siRNA (Dharmacon) using XFect siRNA Transfection Reagent (Clontech, Mountain View, CA, USA) according to the manufacturer's recommendations. Downregulation of CUL4A expression was monitored at the protein level by western blot 48 and $72 \mathrm{~h}$ post transfection.

Ectopic CUL4A overexpression by transient plasmid transfection. For ectopic overexpression, $5 \times 10^{5}$ cells were transiently transfected with $1 \mu \mathrm{g}$ CUL4A- or eGFP-encoding expression vectors using Lipofectamine2000 reagent (Thermo Scientific) according to the manufacturer's recommendations. pcDNA3HA2-CUL4A was a gift from Yue Xiong (Addgene plasmid \# 19907; $\mathrm{Hu}$ et al, 2008). The eGFP-encoding expression vector pEGFP-N3 was kindly provided by Michael Grusch (Institute of Cancer Research, Medical University of Vienna) and served as transfection control. $48 \mathrm{~h}$ post transfection, cells were seeded for cell viability assay and CUL4A overexpression was verified by western blot.

In vivo xenograft growth and therapy. Animal experiments were authorised by the Ethics committee of the Medical University of Vienna and carried out according to the guidelines of the Federation of Laboratory Animal Science Associations (FELASA) as well as to the Arrive guidelines for animal care and protection, also strongly considering the strategies to replace, reduce, and refine ('3R'). Animals were removed from study upon excessive tumour burden $(>1.5 \mathrm{~cm}$ diameter), tumour ulceration or animal weight loss ( $>15 \%$ compared with pre-treatment weight), in accordance with the guidelines for the welfare and use of animals in cancer research, as well as meeting the FELASA guidelines' definition of humane endpoints (Workman et al, 2010). Sixteen 8-week-old female CB-17 scid/scid (SCID) mice were obtained from Harlan Laboratories (San Pietro al Natisone, Italy). For xenograft experiments, $1 \times 10^{6}$ HCT116 or HCT116/Y1 cells as well as their p53-/ - counterparts (diluted in RPMI) were injected subcutaneously into the right flank. Five days after engraftment, mice received $3 \mathrm{mg}$ cisplatin $/ \mathrm{kg}$ bodyweight (dissolved in $100 \mu \mathrm{l}$ serum-free RPMI) intravenously. Treatment was repeated every 7 days for 4 weeks. Animals in the control group received solvent (RPMI). Bodyweight was measured regularly and tumour growth was monitored by caliper 
measurement. Tumour volume was calculated using the formula $\left(\right.$ length $\times$ width $\left.^{2}\right) / 2$.

Immunohistochemistry. Tumour tissues were formalin-fixed, paraffin-embedded and sectioned at $4 \mu \mathrm{m}$. Tissue sections were deparaffinised and rehydrated. Tissue sections were treated with Heat Induced Antigen Retrieval (HIER) for $10 \mathrm{~min}$ in $10 \mathrm{mM}$ citrate buffer ( $\mathrm{pH} 6.0$ ), incubated with rabbit $\mathrm{mAb}$ anti-phosphoH2AX (Ser139, 1:100) for $1 \mathrm{~h}$, or with Ki67 mouse mAb (Dako, Glostrup, Denmark, 1:100) for $30 \mathrm{~min}$, followed by treatment with Ultravision Labelled HRP polymer (UVLP, Dako, Glostrup, Denmark, incubation time $15 \mathrm{~min}$ ). Antibody binding was visualised with $\mathrm{DAB}+$ chromogen and sections were counterstained with hematoxylin (Sigma). To visualise histology as well as live and dead cells, tissue sections were stained with hematoxylin and eosin (H\&E, Sigma).

Statistical analysis. Data are expressed as mean \pm s.d. The values given show one representative experiment out of at least three independent experiments performed in triplicates. Results were analysed using GraphPad Prism software. Statistical analyses were performed using $t$-test or two-way analysis of variance (ANOVA) or Logrank Test. To examine differences between drug treatment responses, Bonferroni post-tests were conducted. $P$-values below 0.05 were considered as statistically significant and marked with stars: ${ }^{\star} P<0.05 ;{ }^{* *} P<0.01 ;{ }^{* *} P<0.001$.

\section{RESULTS}

Selection of HCT116 cells for acquired trabectedin resistance results in stable hypersensitivity towards cisplatin. The human CRC cell line HCT116 shows marked sensitivity towards trabectedin with an $\mathrm{IC}_{50}$ value in the low nanomolar range.
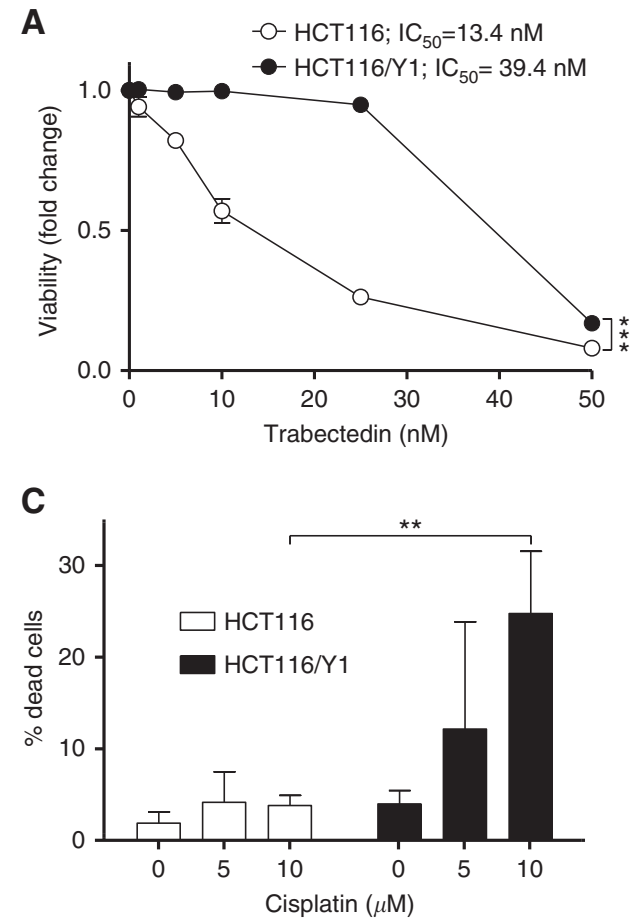

Long-term culturing of HCT116 cells in the presence of trabectedin resulted in pronounced unresponsiveness towards the selection drug in the generated subline (designated HCT116/Y1, Figure 1A). To detect potentially altered responsiveness of HCT116/Y1 cells towards other anticancer agents, we performed a cross-cytotoxicity screen, testing the activities of various drugs approved for the treatment of colorectal cancer as well as other chemotherapeutic agents (Supplementary Table 1). No cross-resistance against any of the tested compounds was observed. In contrast, we identified HCT116/Y1 cells to be strongly hypersensitive towards the platinum compounds cisplatin and carboplatin, shifting the $\mathrm{IC}_{50}$ value in the case of cisplatin into a sub-micromolar range (Figure 1B). This distinct effect proved to be stable, as removal of trabectedin selection pressure from HCT116/Y1 cells over 6 months did not result in reversal of cisplatin hyperactivity (HCT116/Y1R, Figure 1B). Furthermore, we generated a trabectedin-selected subline of the isogenic HCT116 p53 - / - counterpart (HCT116-p53KO). This subline (HCT116-p53KO/Y1) also exhibited strong and stable hypersensitivity towards cisplatin (Supplementary Figure S1A), indicating that p53 signalling is not essential in cisplatin hyperactivity in trabectedin-selected cells. Both, HCT116/Y1 and HCT116-p53KO/Y1 cells, exhibited strongly increased cell death rates after $24 \mathrm{~h}$ cisplatin treatment as compared with their parental counterparts (Figure 1C, Supplementary Figure S1B, respectively). Of note, hypersensitivity towards platinumbased chemotherapeutic agents appeared to be cisplatin specific, as the activity of oxaliplatin was widely unaltered in the trabectedinselected sublines as compared with parental cell lines (Figure 1D, Supplementary Figure S1C).

HCT116/Y1 cells exhibit impaired G2/M cell cycle arrest and increased apoptosis induction upon cisplatin treatment. Consequently, we investigated whether hypersensitivity of HCT116/Y1 cells is associated with alterations in the cell cycle distribution upon

B
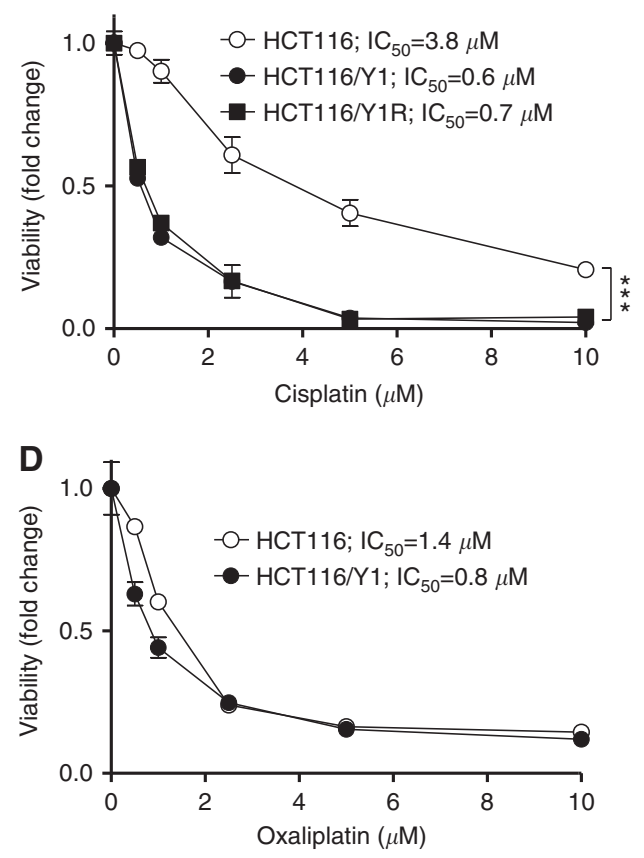

Figure 1. Selection of HCT116 cells for trabectedin resistance results in stable hypersensitivity towards cisplatin. (A) Sensitivity of HCT116 and HCT116/Y1 cells upon $72 \mathrm{~h}$ trabectedin exposure was analysed by MTT assay. ${ }^{\star \star \star} P<0.001$, two-way ANOVA, Bonferroni post-test. (B) Hypersensitivity of HCT116/Y1 cells and their revertant subline (6 months drug-free) towards cisplatin, determined by MTT assay. ${ }^{\star \star \star} P<0.001$, two-way ANOVA, Bonferroni post-test. (C) Cell death induction of HCT116 and HCT116/Y1 cells, analysed by PI staining and FACS after $24 \mathrm{~h}$ cisplatin treatment. ${ }^{* *} P<0.01$, unpaired t-test. (D) Viability of oxaliplatin-treated HCT116 cells and their trabectedin-selected subline, analysed by MTT assay. 
cisplatin-induced DNA damage. FACS analysis of HCT116 cells treated with cisplatin for $48 \mathrm{~h}$ revealed a massive, dose-dependent $\mathrm{G} 2 / \mathrm{M}$ cell cycle phase arrest, reaching a maximum at $10 \mu \mathrm{M}$ (Figure 2A, left panel). In parallel, the fraction of cells in S-phase was strongly reduced. In contrast, changes in cell cycle distribution of cisplatin-treated HCT116/Y1 cells were markedly less pronounced (Figure 2A, right panel). This indicates an impaired capability of the subline to initiate DNA damage response following exposure to cisplatin resulting in reduced cell cycle arrest. However, treatment with $10 \mu \mathrm{M}$ cisplatin resulted in strong upregulation of the DNA damage sensors and cell cycle gatekeepers p53 and p21 in both, parental and HCT116/Y1 cells (5.4-fold vs 5.2-fold for p53 and 1.3-fold vs 8.5-fold for p21, respectively; Figure 2B). Interestingly, HCT116/Y1 cells exhibited slightly elevated basal levels of the pro-apoptotic factor Bax. Cisplatin treatment resulted in strong upregulation of Bax in both cell lines. This effect seemed distinctly stronger in HCT116/Y1 cells (1.6-fold vs 3.3-fold, respectively; Figure 2B). Accordingly, FACS analysis of Annexin V-stained cells revealed massive apoptosis induction in HCT116/Y1 cells treated for $24 \mathrm{~h}$ with cisplatin, whereas this effect was only minor in the parental line (Figure 2C).

Furthermore, we found the trabectedin-selected subline to be hypersensitive to TRAIL-mediated apoptosis (Figure 2D). In contrast, cotreatment with the pan caspase inhibitor Z-VADFMK distinctly desensitised HCT116/Y1 cells towards cisplatin (Figure 2E). This effect was also seen in the parental line, albeit to a lesser extent as compared with the selected subline (1.56-fold vs 2-fold, respectively). Taken together, this suggests that

A

HCT116

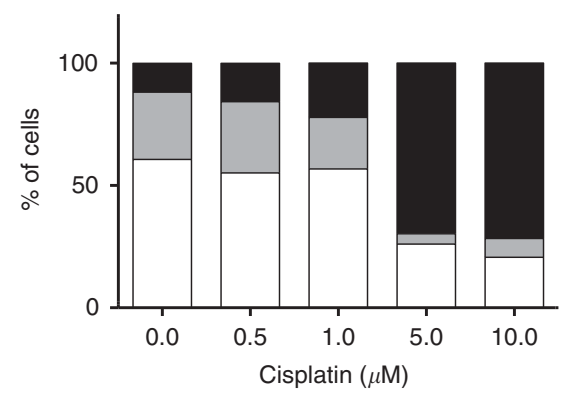

B

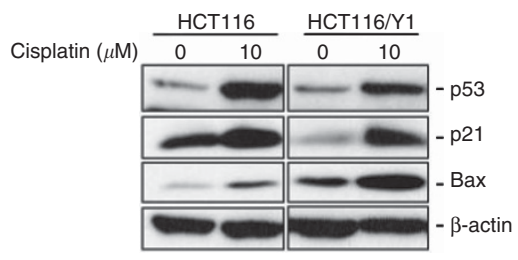

D

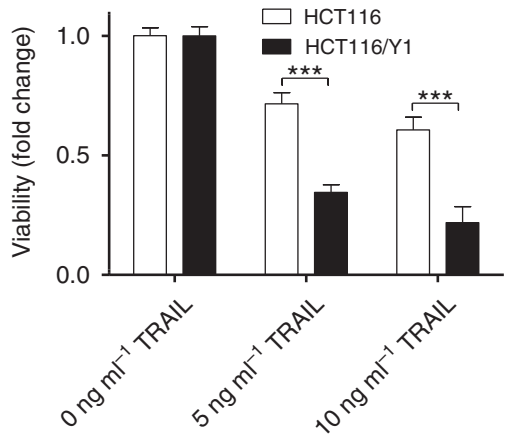

HCT116/Y1

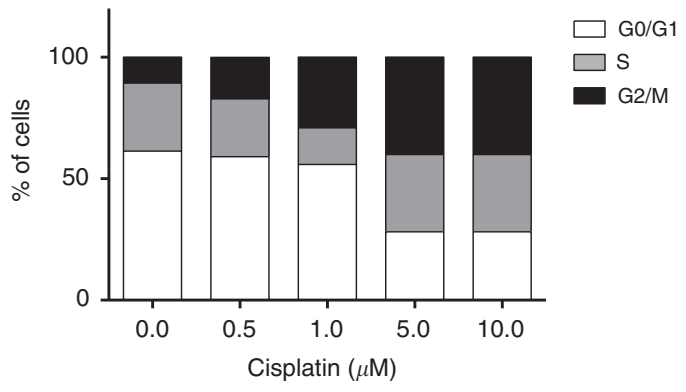

C

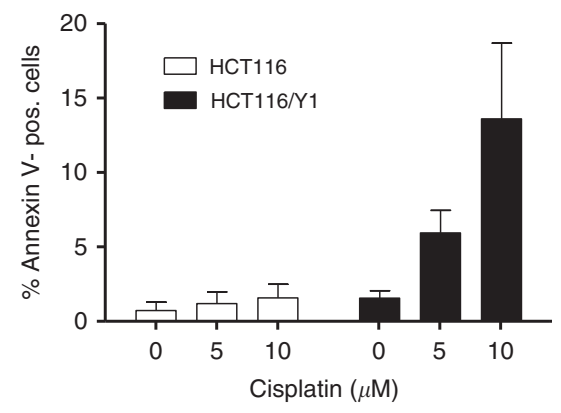

E

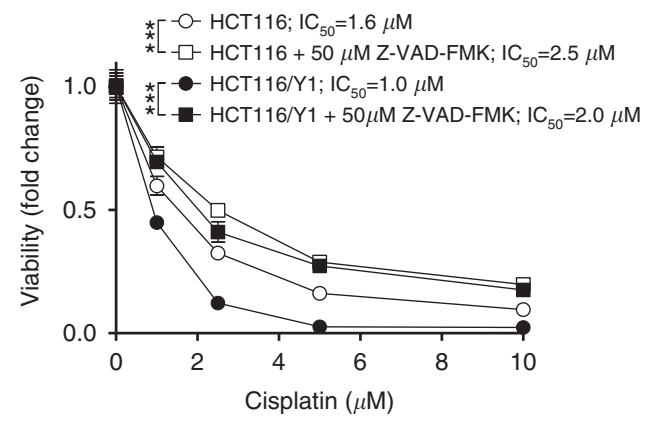

Figure 2. Impaired G2/M arrest and increased apoptosis induction in HCT116/Y1 cells upon treatment with cisplatin. (A) The effect of $48 \mathrm{~h}$ cisplatin treatment on cell cycle distribution of HCT116/Y1 and their parental cells, determined by PI staining and FACS. (B) Expression of p53, p21, and Bax in HCT116 and HCT116/Y1 cells, treated for $24 \mathrm{~h}$ with cisplatin, analysed by western blot. B-actin served as loading control. (C) Apoptotic cell death induction after $24 \mathrm{~h}$ cisplatin treatment, analysed by Annexin V/PI-staining and FACS. (D) Viability of HCT116 and HCT116/Y1 cells upon $72 \mathrm{~h}$ exposure to TRAIL, analysed by MTT assay. ${ }^{\star \star \star} P<0.001$, unpaired $t$-test. (E) Effect of $50 \mu \mathrm{M}$ pan-caspase inhibitor Z-VAD-FMK on viability of HCT116 and HCT116/Y1 cells upon $72 \mathrm{~h}$ cisplatin treatment, determined by MTT assay. ${ }^{* \star *} P<0.001$, two-way ANOVA, Bonferroni post-test. 
pro-apoptotic cascades are hyperactivated in HCT116/Y1 cells favoring cisplatin-mediated cell death.

Exposure of HCT116/Y1 cells to cisplatin results in stronger DNA platination and impaired DNA damage repair. The observed hypersensitivity of HCT116/Y1 cells towards cisplatin prompted us to investigate whether increased cytotoxicity is accompanied by an altered intracellular accumulation of the drug. Indeed, ICP-MS analysis of genomic DNA isolated from cells treated with cisplatin for $24 \mathrm{~h}$ revealed enhanced platination levels in the HCT116/Y1 subline as compared with parental cells (Figure 3A). In parallel, incubation of HCT116/Y1 cells with increasing concentrations of cisplatin for $1 \mathrm{~h}$ followed by an $8 \mathrm{~h}$ recovery phase before DNA strand break-inducing $\mathrm{H}_{2} \mathrm{O}_{2}$ treatment led to a significant, dose-dependent decrease in comet tail intensities. This effect could not be observed in the parental cells (Figure 3B). This indicates that $8 \mathrm{~h}$ after cisplatin exposure, HCT116/Y1 cells exhibit strongly elevated levels of DNA
A

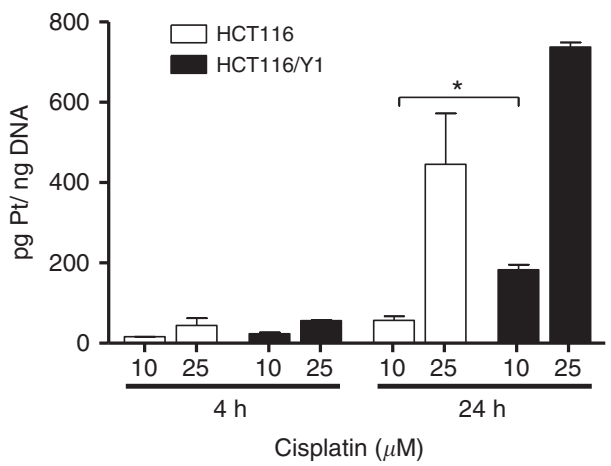

B

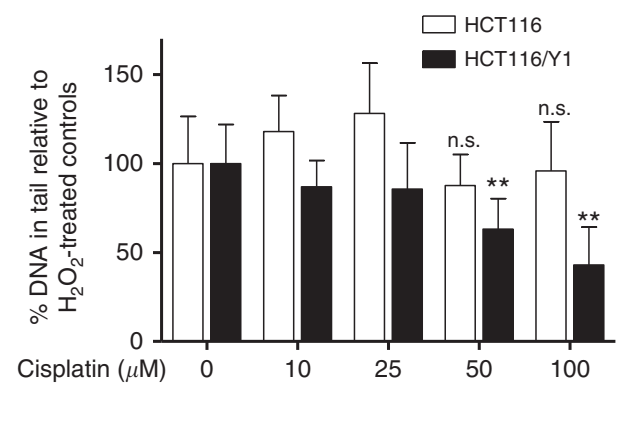

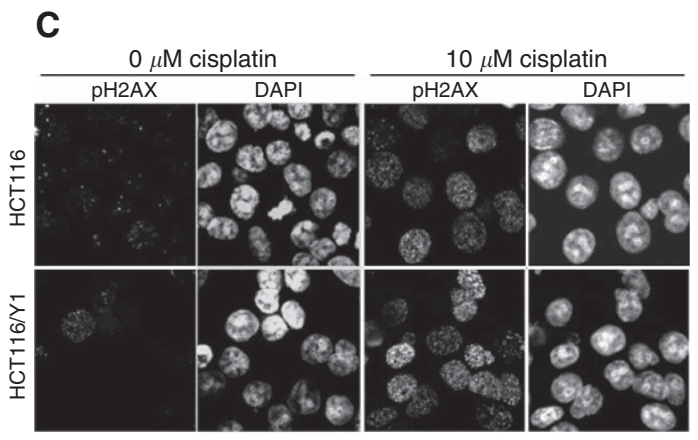

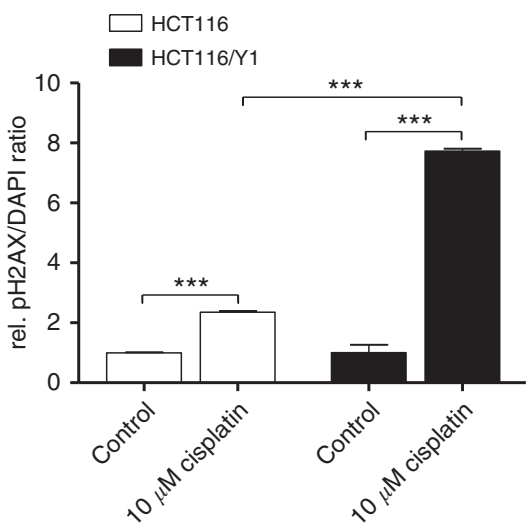

D
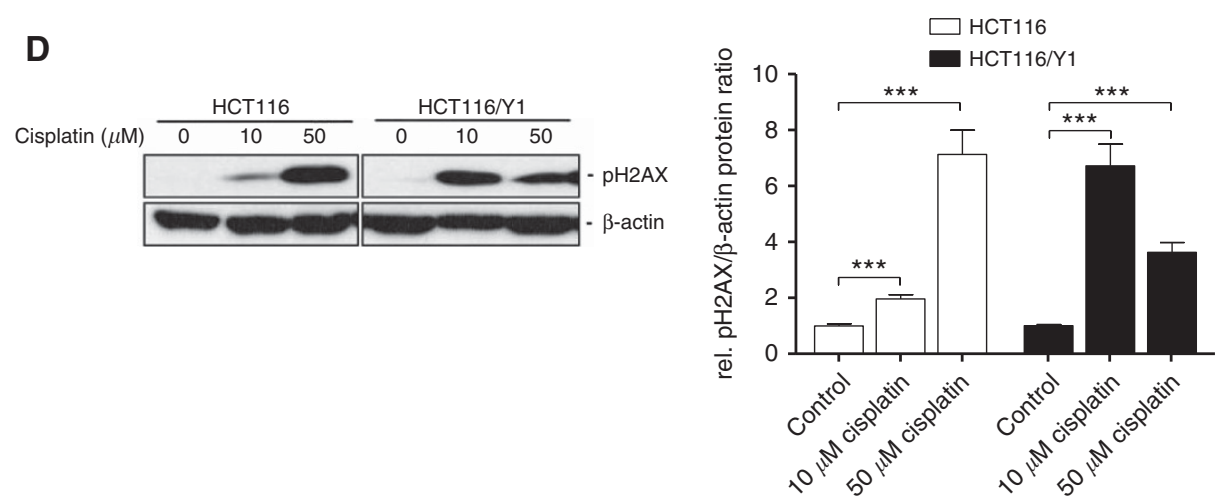

Figure 3. HCT116/Y1 cells exhibit higher DNA platination levels and impaired DNA damage repair upon cisplatin treatment. (A) DNA platination levels of cisplatin-treated HCT116 and HCT116/Y1 cells, determined by ICP-MS. ${ }^{*} P<0.05$, unpaired t-test. (B) Levels of cisplatin-induced DNA crosslinks in HCT116 and HCT116/Y1 cells, analysed by modified alkaline comet assay. Cells were treated with cisplatin for $1 \mathrm{~h}$. After $8 \mathrm{~h}$ recovery, cells were treated with $50 \mu \mathrm{M} \mathrm{H} \mathrm{H}_{2}$ for $1 \mathrm{~h}$ and DNA fragmentation was determined measuring tail intensities of damaged nuclei in SCGE assay. Data are presented as \% DNA in tail relative to $\mathrm{H}_{2} \mathrm{O}_{2}$-treated controls. ${ }^{\star \star} P<0.01$, unpaired t-test. n.s., non-significant; $(\mathbf{C}, \mathbf{D})$ Effect of $24 \mathrm{~h}$ cisplatin treatment of HCT116 and HCT116/Y1 cells on phosphorylation levels of histone H2AX, determined by confocal immunofluorescence microscopy (C) and western blot (D). (C) Nuclei were counterstained with 4',6-diamidino-2-phenylindole (DAPI). Representative photomicrographs (left panel) are opposed to quantification of $\mathrm{pH} 2 \mathrm{AX}$ immune-staining normalised to DAPI (right panel). (D) B-actin served as protein loading control. A representative western blot experiment (left panel) and quantification of protein levels normalised to $\beta$-actin (right panel) are shown. $\star \star \star P<0.001$, unpaired t-test. 
interstrand crosslinks as compared with the parental cells. In line with this, treatment of cells with $10 \mu \mathrm{M}$ and $50 \mu \mathrm{M}$ cisplatin resulted in strong DNA-damage recognition in HCT116/Y1 cells as indicated by enhanced histone $\mathrm{H} 2 \mathrm{AX}$ phosphorylation levels (Figure $3 \mathrm{C}$ and D). Altogether, this indicates that, despite initial damage recognition, successful repair of cisplatin-mediated DNA lesions is impeded in HCT116/Y1 cells as compared with its parental cell line.

The NER-associated ubiquitin ligase CUL4A is downregulated in cisplatin-hypersensitive HCT116/Y1 cells. Next, we addressed the question whether selection of HCT116 cells for trabectedin resistance resulted in gene-dose changes on a genomic level and whether these potential alterations have a role in the propensity of HCT116/Y1 cells to higher levels of cisplatin-induced DNA damage and cell death. Surprisingly, genome-wide aCGH analysis revealed no additional gene-dose alterations in HCT116/Y1 cells as compared with their parental cell line (Supplementary Figure 2).

This prompted us to perform whole-genome gene expression arrays to detect altered mRNA expression patterns. In search of transcriptional alterations potentially underlying cisplatin hypersensitivity, we compared gene expression data of HCT116 and HCT116/Y1 cells by GSEA. Of note, we identified enrichment of the gene ontology (GO) term 'NER' within the Kyoto Encyclopedia of Genes and Genomes (KEGG; Figure 4A and B). In this context, it has to be stated that defective NER has been reported to potentiate cisplatin activity (Welsh et al, 2004). Indeed, analysis of this GO term in our GSEA dataset revealed transcriptional downregulation of several genes encoding key NER factors in HCT116/Y1 cells including POLE4, DDB2, POLD4 and-most potently-CUL4A (Figure 4A). Subsequent analysis on the single gene level revealed CUL4A to be strongly downregulated in HCT116/ Y1 cells both at mRNA and protein levels (Figure 4C and D). CUL4A encodes an E3 ubiquitin ligase involved in the initiation of repair ofamongst others-UV- and cisplatin-induced DNA lesions (Sugasawa, 2009). In line with this, HCT116/Y1 cells proved to be significantly more sensitive towards UV irradiation than the parental cells (Figure 4E). Furthermore, NER inhibition by novobiocin significantly sensitised parental HCT116 cells against cisplatin, whereas this effect was not observed in the trabectedin-selected subline (Figure $4 \mathrm{~F}$ ). Taken together, this suggests that downregulation of CUL4A, together with several other NER proteins, has a functional role in HCT116/Y1 cell hypersensitivity towards cisplatin.

Transient knockdown of CUL4A sensitises HCT116 cells to cisplatin. To investigate whether CUL4A indeed has a role in cisplatin sensitivity of HCT116 cells, we performed transient knockdown experiments. Here, exposure to $50 \mathrm{~nm}$ CUL4A siRNA resulted in distinct downregulation of CUL4A protein levels 48 and $72 \mathrm{~h}$ post-treatment and in a significantly increased sensitivity towards UV-irradiation (Figure 5A and B). Importantly, partial knockdown of this protein led to a significant sensitisation of HCT116 cells to cisplatin (Figure 5C). This effect was also observed upon silencing of CUL4A in two additional CRC cell lines SW480 and DLD-1 (Supplementary Figure S3A and B, respectively). Furthermore, we aimed at elucidating whether restoration of CUL4A expression levels in HCT116/Y1 cells has an impact on cisplatin sensitivity. We thus re-established CUL4A expression in HCT116/Y1 cells by transient plasmid DNA transfection (Figure 5D). Indeed, ectopic CUL4A overexpression resulted in a significant loss of cisplatin sensitivity in comparison to cells left untransfected or transfected with an eGFP-encoding control plasmid (Figure 5E, 1.4-fold increased $\mathrm{IC}_{50}$ values). Altogether, these data show that CUL4A is an important factor counteracting cisplatin-mediated cytotoxicity.

Trabectedin selection confers hypersensitivity of HCT116 cells to cisplatin in vivo. As a next step, we investigated whether the hypersensitivity of trabectedin-selected HCT116 cells towards cisplatin could also be exploited therapeutically in vivo. Therefore, we established subcutaneous tumour xenografts of HCT116 cells and their respective subline in SCID mice. Indeed, treatment of HCT116/Y1-derived xenografts with $3 \mathrm{mg} \mathrm{kg}^{-1}$ cisplatin resulted in significantly reduced tumour growth, whereas growth of tumours derived from parental HCT116 cells was not affected by cisplatin (Figure 6A). A similar effect could be observed in mice bearing p53-/ - HCT116 and HCT116/Y1 tumour counterparts (Supplementary Figure S4). Cisplatin-treated mice bearing HCT116/Y1 tumours survived significantly longer than mice bearing parental tumours but also compared with the untreated cohort (Figure 6B). Immunohistochemical analysis of tumour tissue sections showed significantly increased phosphorylation of histone H2AX indicating elevated levels of DNA damage in cisplatin-treated HCT116/Y1 tumours as compared with their parental counterparts (Figure 6C and D).

\section{DISCUSSION}

Platinum-based chemotherapy constitutes the most widely used treatment modality for cancer (Wheate et al, 2010). Cisplatin is commonly used as a chemotherapeutic agent against a wide variety of carcinomas (Apps et al, 2015). Furthermore, it forms the basis of numerous combination treatment strategies. Cisplatin introduces monoadducts, intra- and interstrand DNA as well as DNA-protein crosslinks, thus inhibiting DNA replication and gene transcription, eventually leading to apoptosis induction (Galluzzi et al, 2014).

Nucleotide excision repair is a versatile DNA repair pathway that eradicates bulky lesions induced by a range of unrelated DNA noxae, including cisplatin-induced helix distortions (Martin et al, 2008). In fact, the NER status has been shown to predict the sensitivity of cancer cells towards cisplatin in various studies (Kelland, 2007; Bowden, 2014). This is illustrated by the fact that, on the one hand, cisplatin resistance of ovarian and lung cancer cells is accompanied by increased DNA repair capacity and, on the other hand, that hypersensitivity of testicular cancers towards cisplatin is a result of NER deficiency (Johnson et al, 1994; Koberle et al, 1999; Welsh et al, 2004). Trabectedin-besides merely interacting with DNA-is believed to exert its cytotoxic activity by formation of ternary complexes with DNA-binding NER proteins, thus impeding effective DNA repair (D'Incalci and Galmarini, 2010). Accordingly, trabectedin was found to exert more potent cytotoxicity in a hyperactive NER background, as encountered for example in cisplatin-resistant cells (Damia et al, 2001).

In CRC, platinum compounds constitute a mainstay of chemotherapeutic intervention (Stein and Arnold, 2012). However, it is currently unknown whether trabectedin might enhance efficacy of platinum drugs in this cancer type. In the current study, we thus elucidated the effects of trabectedin selection and, hence, acquired trabectedin resistance of CRC cells on responsiveness towards platinum compounds. We found strong and stable hypersensitivity of trabectedin-selected HCT116 cells against cisplatin. Gene expression profiling revealed downregulation of several NER pathway members, above all of the ubiquitin ligase CUL4A. Consequently, we identified this DNA repair factor to have a key role in hypersensitivity of HCT116/Y1 cells towards cisplatin. We were able to show that interference with CUL4A expression levels clearly altered the cytotoxic activity of cisplatin. On one hand, this was illustrated by partial cisplatin sensitisation of parental HCT116 and two other colon cancer cell lines upon siRNA-mediated CUL4A knockdown. On the other hand, HCT116/Y1 cells were desensitised against cisplatin upon ectopic overexpression of CUL4A. The observed acquired NER deficiency is in accordance with a recent publication by Colmegna et al., 


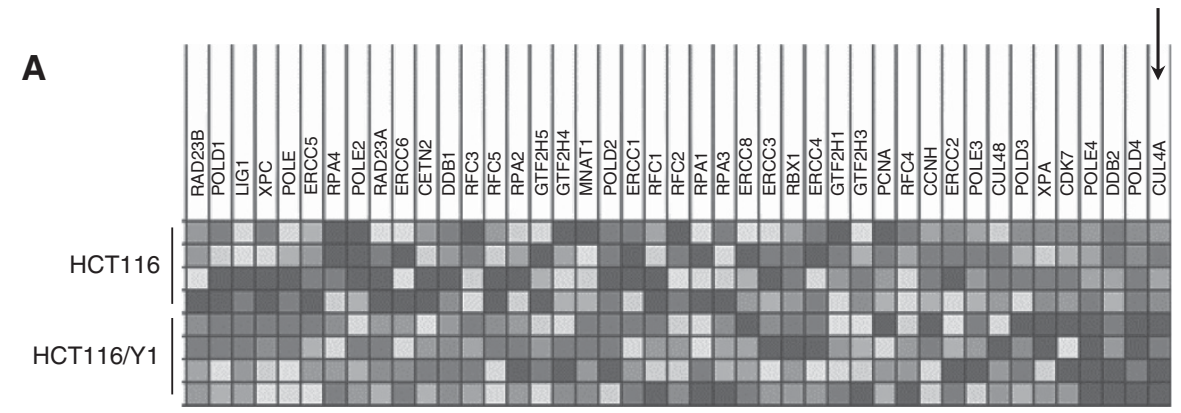

B

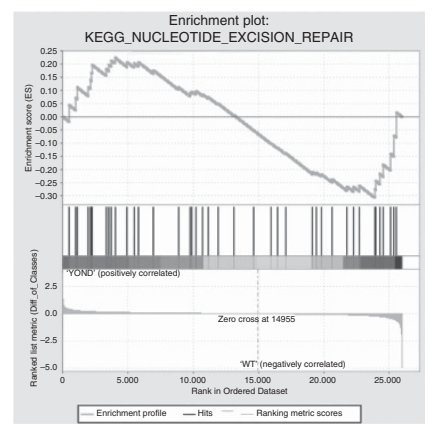

C
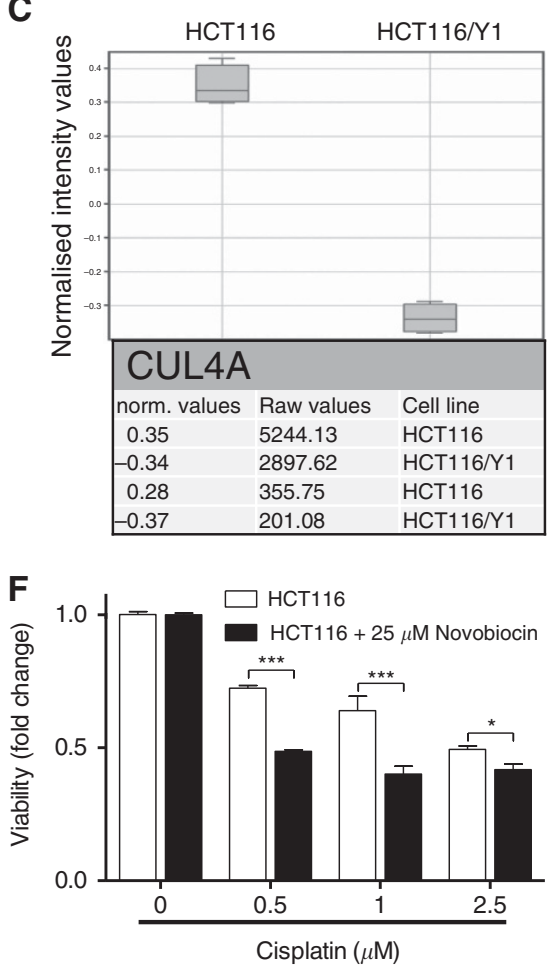

D

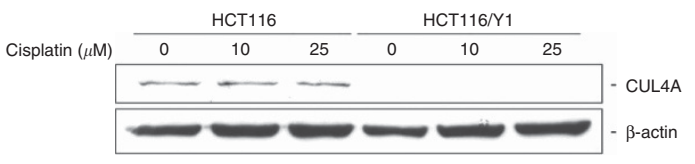

E
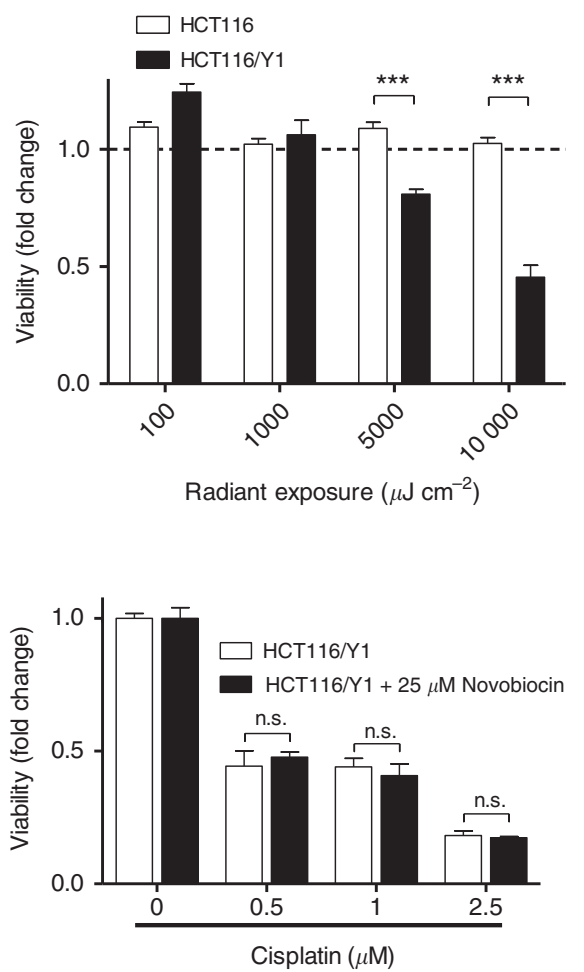

Figure 4. Trabectedin selection of HCT116 cells results in transcriptional downregulation of CUL4A and impaired nucleotide excision repair. (A, B) GSEA of whole genome gene expression data revealed significant enrichment of the pathway interaction database-derived GO term 'Nucleotide Excision Repair' for downregulation in HCT116/Y1 as compared with HCT116 cells. Genes within this GO term are depicted as heatmap (A) and as enrichment plot (B) and identified CUL4A as the top downregulated gene in HCT116/Y1 cells (indicated by an arrow). (C) Whole genome gene expression data reveal transcriptional downregulation of CUL4A (Box plot). The lower panel shows the mean normalised and raw values (4 replicas) for the two CUL4A oligonucleotides on the array. (D) Protein expression levels of CUL4A, determined by western blot. B-actin served as loading control. (E) Viability of UV-irradiated HCT116 and HCT116/Y1 cells, analysed $72 \mathrm{~h}$ post-exposure by MTT assay. Bars are shown relative to untreated controls. ${ }^{\star \star \star} P<0.001$, unpaired t-test. (F) Viability of HCT116 (left panel) and HCT116/Y1 cells (right panel) upon $72 \mathrm{~h}$ exposure to cisplatin in presence of the NER inhibitor novobiocin, analysed by MTT assay. ${ }^{\star \star \star} P<0.001,{ }^{\star \star} P<0.01$, two-way ANOVA, Bonferroni post-test. n.s., not significant.

reporting the downregulation of several NER-associated factors in myxoid liposarcoma and ovarian carcinoma cell models in response to trabectedin selection, which also resulted in hypersensitivity towards platinum drugs as well as UV irradiation
(Colmegna et al, 2015). Another study described inverse correlation of cisplatin and trabectedin sensitivity of ovarian and CRC cell models with defects of various NER proteins (Stevens et al, 2008). 
A
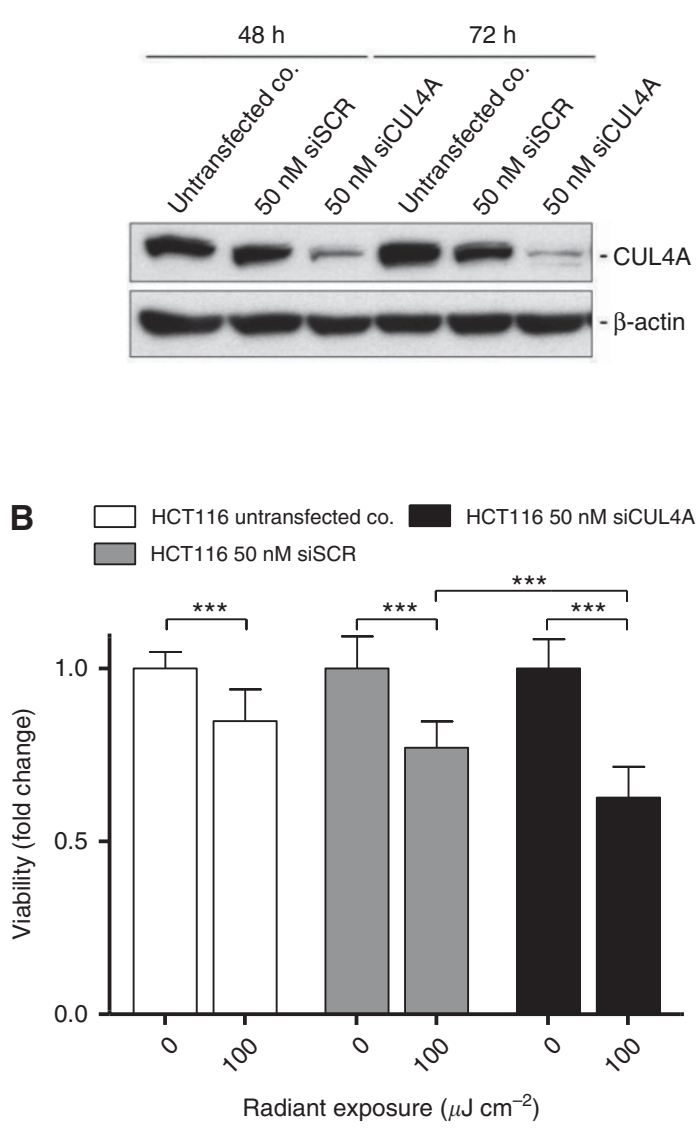

D

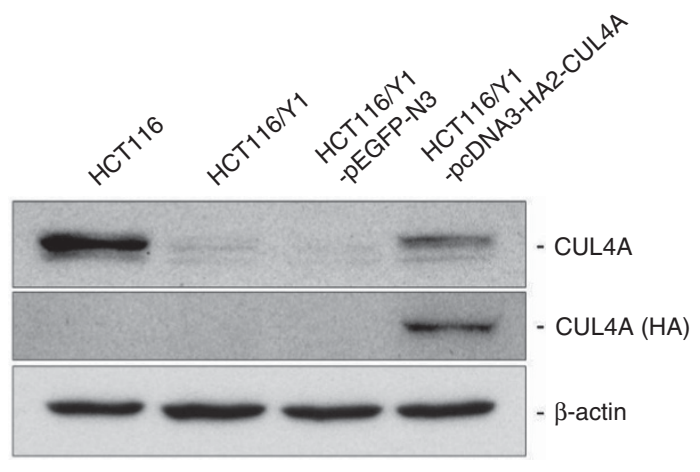

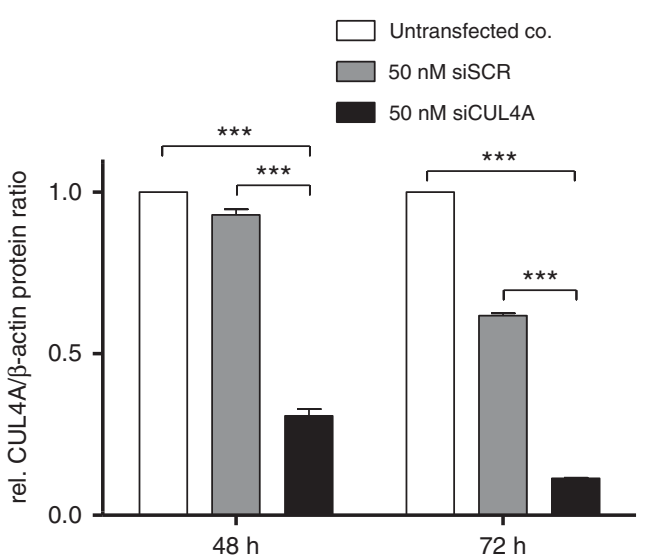

C

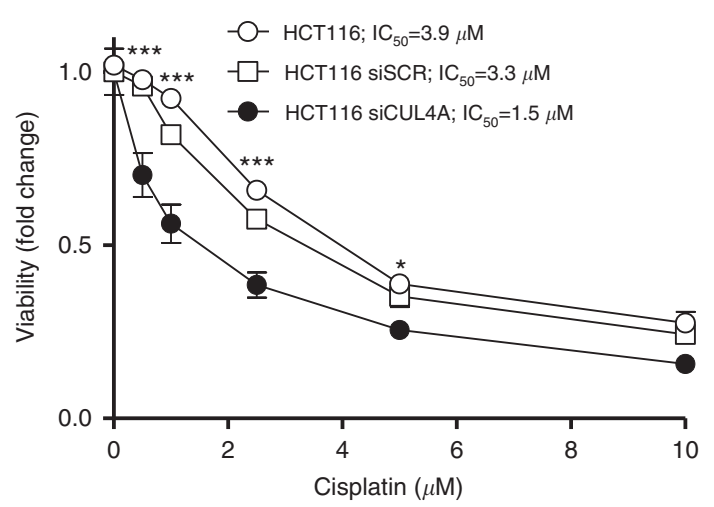

E

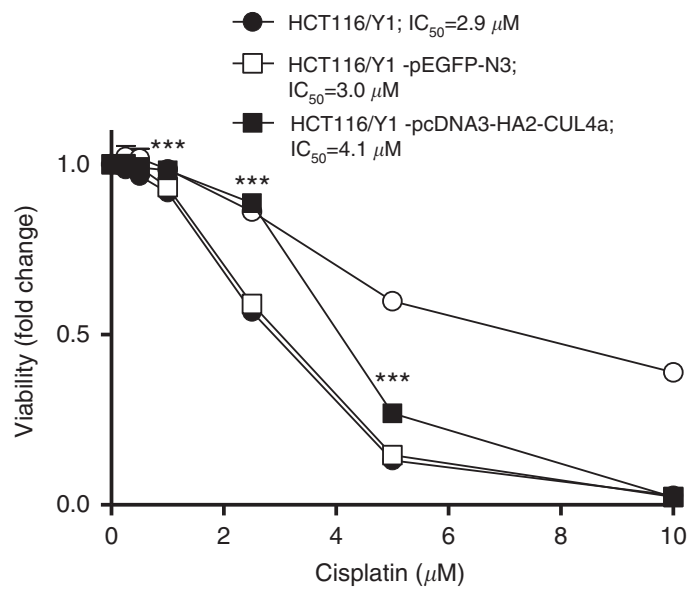

Figure 5. CUL4A sensitises HCT116 cells towards cisplatin. (A-C) Transient siRNA knockdown of CUL4A in HCT116 cells. (A) Impact of 50 nM siCUL4A knockdown on CUL4A protein levels, analysed by western blot (left panel). $50 \mathrm{~nm}$ non-targeted siRNA (siSCR) served as transfection control. Extent of CUL4A downregulation was determined calculating relative CUL4A/B-actin protein ratios (right panel). ${ }^{\star \star \star} P<0.001$, unpaired $t$-test. (B) Viability of siRNA-treated, UV-irradiated HCT116 cells was analysed by MTT assay $72 \mathrm{~h}$ post-exposure. ${ }^{\star \star \star} P<0.001$, unpaired $t$-test. (C) Viability of siRNA-treated HCT116 cells upon $72 \mathrm{~h}$ exposure to cisplatin, analysed by MTT assay. ${ }^{*} P<0.05$, ${ }^{\star * \star} P<0.001$, two-way ANOVA, Bonferroni post-test. (D) Protein levels of ectopically overexpressed CUL4A were analysed by western blot $48 \mathrm{~h}$ post transfection. (E) $48 \mathrm{~h}$ post transfection with $1 \mu \mathrm{g}$ pcDNA3-HA2-CUL4A, viability of HCT116/Y1 cells treated with indicated concentrations of cisplatin was analysed by MTT assay. pEGFP-N3 served as transfection control. ${ }^{\star \star \star} P<0.001$, unpaired t-test.

In general, data on the relationship between NER functionality and sensitivity towards platinum compounds are conflicting, as several studies also reported high expression of NER proteins in a cisplatin-responsive background (Stevens et al, 2005; Weaver et al, 2005). Nevertheless, downregulation of multiple NER factors associated with enhanced sensitivity towards platinum drugs has been described in NSCLC, testicular, and also in CRC cell lines (Rosell et al, 2003; Rabik and Dolan, 2007; Stubbert et al, 2010). These factors primarily concern ERCC1, XPG (ERCC5) as well as XPF (ERCC4), all involved in the NER-associated DNA incision 
A

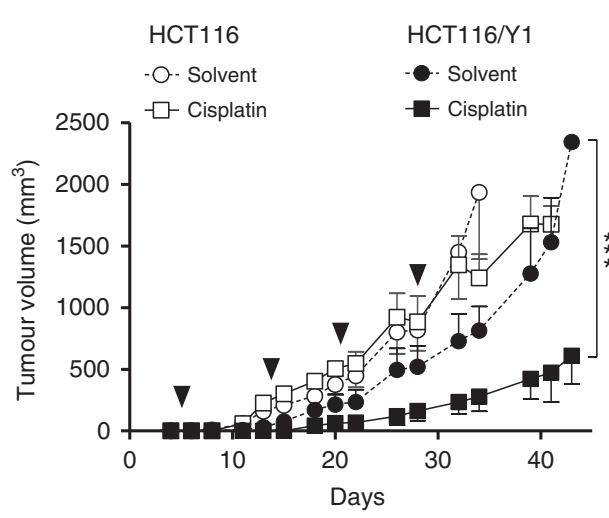

C

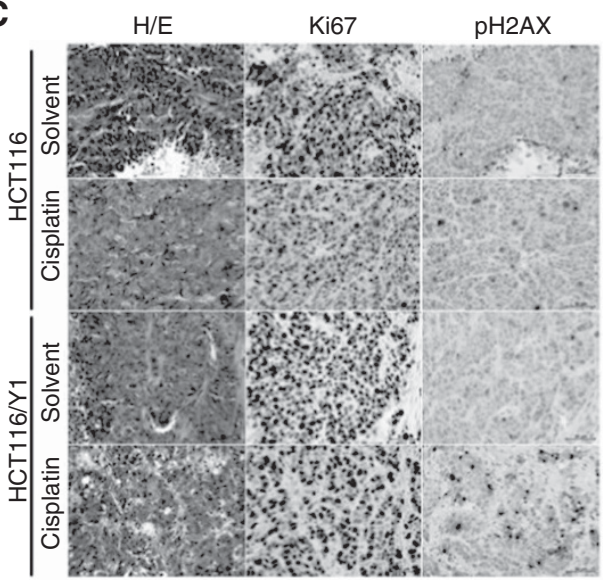

B

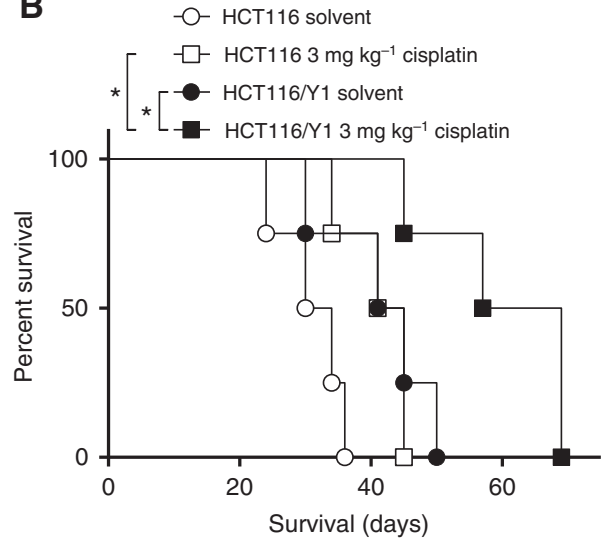

D

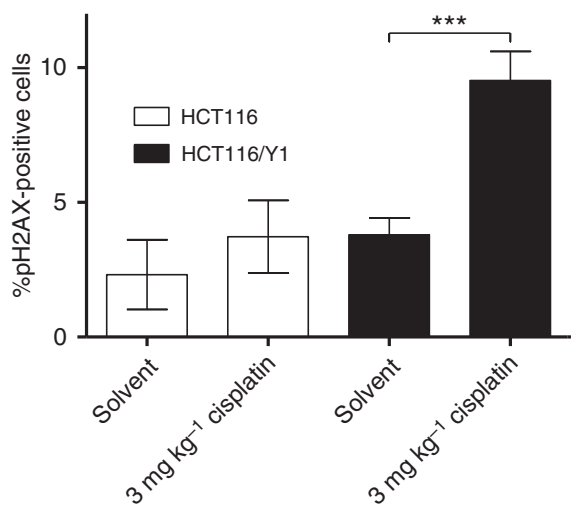

Figure 6. Trabectedin-selected HCT116 cells are hypersensitive towards cisplatin also in vivo. (A) Efficacy of cisplatin on HCT116 and HCT116/Y1 subcutaneous xenograft growth. Days of treatment are indicated by the arrows. ${ }^{\star \star \star} P<0.001$, two-way ANOVA, Bonferroni post-test. (B) Effect of cisplatin treatment on survival of xenografted mice. Survival is given as days post-engraftment. ${ }^{\star} P<0.05$, ${ }^{\star \star} P<0.01$, logrank test. Animals were removed from study upon excessive tumour burden ( $>1.5 \mathrm{~cm}$ diameter), tumour ulceration or animal weight loss ( $>15 \%$ compared with pre-treatment weight), in accordance with the guidelines for the welfare and use of animals in cancer research. (C) Effect of cisplatin treatment on phosphorylation of H2AX in tumour xenografts, analysed by immunohistochemistry. Histology was visualised by haematoxylin/eosin (H/E) staining, proliferating tumour regions were stained by Ki67. (D) Percentage of pH2AX-positive cells was determined counting three independent microscopic fields for each treatment group. ${ }^{\star \star \star} P<0.001$, unpaired $t$-test.

process (Takebayashi et al, 2001b; Bowden, 2014). Interestingly, analysis of our cell model by gene expression arrays revealed no alterations in expression of all these factors. In contrast, the here reported downregulation of CUL4A expression as a consequence of cancer cell selection against trabectedin has to our knowledge so far neither been reported nor associated with cisplatin hypersensitivity. Thus far, high CUL4A levels have only been described as a predictive marker for trabectedin response in breast cancer and a publication by Yang et al. reported transient knockdown of CUL4A to sensitise lung cancer cells towards cisplatin (Garcia et al, 2013; Yang et al, 2014). Our work thus provides evidence that downregulation of the NER factor CUL4A due to selection for trabectedin resistance is a novel mechanism to sensitise CRC cells against cisplatin. Additionally, it strengthens the assumption that CUL4A expression level represents a biomarker to predict cisplatin responsiveness.

Importantly, HCT116/Y1 cells were also hypersensitive towards the cisplatin analogue carboplatin (Supplementary Table 1; Supplementary Figure S5). As this was not the case for oxaliplatin, we hypothesise that hypersensitivity of trabectedin-selected HCT116 CRC cells is specific for cisplatin- and carboplatininduced DNA lesions, which are distinct from those formed by oxaliplatin (Bowden, 2014). Supporting this hypothesis, a report of Colmegna et al. describes a concomitant sensitisation of trabectedin-selected myxoid liposarcoma and ovarian carcinoma cell models against cisplatin and carboplatin (Colmegna et al, 2015).

In conclusion, our data suggest CUL4A downregulationmediated NER deficiency as a novel mechanism inducing both trabectedin resistance and collateral cisplatin hypersensitisation. Hence, inclusion of trabectedin in platinum compound-containing treatment regiments should reciprocally counteract resistance development and, consequently, impede therapy failure.

\section{ACKNOWLEDGEMENTS}

We gratefully thank Mirjana Stojanovic and Gerhard Zeitler for competent technical assistance.

\section{CONFLICT OF INTEREST}

The authors declare no conflict of interest. 


\section{REFERENCES}

Apps MG, Choi EH, Wheate NJ (2015) The state-of-play and future of platinum drugs. Endocr Relat Cancer 22(4): R219-R233.

Bonfanti M, La Valle E, Fernandez Sousa Faro JM, Faircloth G, Caretti G, Mantovani R, D'Incalci M (1999) Effect of ecteinascidin-743 on the interaction between DNA binding proteins and DNA. Anticancer Drug Des 14(3): 179-186.

Bowden NA (2014) Nucleotide excision repair: why is it not used to predict response to platinum-based chemotherapy? Cancer Lett 346(2): 163-171.

Cohen MH, Gootenberg J, Keegan P, Pazdur R (2007) FDA drug approval summary: bevacizumab plus FOLFOX4 as second-line treatment of colorectal cancer. Oncologist 12(3): 356-361.

Colmegna B, Uboldi S, Erba E, D'Incalci M (2014) Resistance to minor groove binders. Drug Discov Today Technol 11: 73-79.

Colmegna B, Uboldi S, Frapolli R, Licandro SA, Panini N, Galmarini CM, Badri N, Spanswick VJ, Bingham JP, Kiakos K, Erba E, Hartley JA, D'Incalci M (2015) Increased sensitivity to platinum drugs of cancer cells with acquired resistance to trabectedin. Br J Cancer 113(12): 1687-1693.

D'Incalci M, Galmarini CM (2010) A review of trabectedin (ET-743): a unique mechanism of action. Mol Cancer Ther 9(8): 2157-2163.

Damia G, Silvestri S, Carrassa L, Filiberti L, Faircloth GT, Liberi G, Foiani M, D'Incalci M (2001) Unique pattern of ET-743 activity in different cellular systems with defined deficiencies in DNA-repair pathways. Int J Cancer 92(4): 583-588.

Demetri GD, von Mehren M, Jones RL, Hensley ML, Schuetze SM, Staddon A, Milhem M, Elias A, Ganjoo K, Tawbi H, Van Tine BA, Spira A, Dean A, Khokhar NZ, Park YC, Knoblauch RE, Parekh TV, Maki RG, Patel SR (2016) Efficacy and safety of trabectedin or dacarbazine for metastatic liposarcoma or leiomyosarcoma after failure of conventional chemotherapy: results of a Phase III randomized multicenter clinical trial. J Clin Oncol 34(8): 786-793.

Galluzzi L, Vitale I, Michels J, Brenner C, Szabadkai G, Harel-Bellan A, Castedo M, Kroemer G (2014) Systems biology of cisplatin resistance: past, present and future. Cell Death Dis 5: e1257.

Ganjoo KN, Patel SR (2009) Trabectedin: an anticancer drug from the sea Expert Opin Pharmacother 10(16): 2735-2743.

Garcia MJ, Saucedo-Cuevas LP, Munoz-Repeto I, Fernandez V, Robles MJ, Domingo S, Palacios J, Aracil M, Nieto A, Tercero JC, Benitez J (2013) Analysis of DNA repair-related genes in breast cancer reveals CUL4A ubiquitin ligase as a novel biomarker of trabectedin response. Mol Cancer Ther 12(4): 530-541.

Heffeter P, Bock K, Atil B, Reza Hoda MA, Korner W, Bartel C, Jungwirth U, Keppler BK, Micksche M, Berger W, Koellensperger G (2010) Intracellular protein binding patterns of the anticancer ruthenium drugs KP1019 and KP1339. J Biol Inorg Chem 15(5): 737-748.

Heffeter P, Popovic-Bijelic A, Saiko P, Dornetshuber R, Jungwirth U, Voevodskaya N, Biglino D, Jakupec MA, Elbling L, Micksche M, Szekeres T, Keppler BK, Graslund A, Berger W (2009) Ribonucleotide reductase as one important target of [Tris(1,10-phenanthroline)lanthanum(III)] trithiocyanate (KP772). Curr Cancer Drug Targets 9(5): 595-607.

Herrero AB, Martin-Castellanos C, Marco E, Gago F, Moreno S (2006) Crosstalk between nucleotide excision and homologous recombination DNA repair pathways in the mechanism of action of antitumor trabectedin. Cancer Res 66(16): 8155-8162.

Hu J, Zacharek S, He YJ, Lee H, Shumway S, Duronio RJ, Xiong Y (2008) WD40 protein FBW5 promotes ubiquitination of tumor suppressor TSC2 by DDB1-CUL4-ROC1 ligase. Genes Dev 22(7): 866-871.

Johnson SW, Swiggard PA, Handel LM, Brennan JM, Godwin AK, Ozols RF, Hamilton TC (1994) Relationship between platinum-DNA adduct formation and removal and cisplatin cytotoxicity in cisplatin-sensitive and -resistant human ovarian cancer cells. Cancer Res 54(22): 5911-5916.

Kelland L (2007) The resurgence of platinum-based cancer chemotherapy. Nat Rev Cancer 7(8): 573-584.

Koberle B, Masters JR, Hartley JA, Wood RD (1999) Defective repair of cisplatin-induced DNA damage caused by reduced XPA protein in testicular germ cell tumours. Curr Biol 9(5): 273-276.

Larsen AK, Galmarini CM, D'Incalci M (2016) Unique features of trabectedin mechanism of action. Cancer Chemother Pharmacol 77(4): 663-671.

Laszlo V, Hoda MA, Garay T, Pirker C, Ghanim B, Klikovits T, Dong YW, Rozsas A, Kenessey I, Szirtes I, Grusch M, Jakopovic M, Samarzija M, Brcic L, Kern I, Rozman A, Popper H, Zochbauer-Muller S, Heller G,
Altenberger C, Ziegler B, Klepetko W, Berger W, Dome B, Hegedus B (2015) Epigenetic down-regulation of integrin alpha7 increases migratory potential and confers poor prognosis in malignant pleural mesothelioma. $J$ Pathol 237(2): 203-214.

Li J, Qin S, Xu R, Yau TC, Ma B, Pan H, Xu J, Bai Y, Chi Y, Wang L, Yeh KH, Bi F, Cheng Y, Le AT, Lin JK, Liu T, Ma D, Kappeler C, Kalmus J, Kim TW, Investigators C (2015) Regorafenib plus best supportive care versus placebo plus best supportive care in Asian patients with previously treated metastatic colorectal cancer (CONCUR): a randomised, double-blind, placebocontrolled, phase 3 trial. Lancet Oncol 16(6): 619-629.

Lieberman R (2012) Food and Drug Administration approval of cetuximab and a new KRAS genetic test for metastatic colorectal cancer: major advance but just the tip of the biomarker iceberg. Am J Ther 19(6): 395-396.

Marteijn JA, Lans H, Vermeulen W, Hoeijmakers JH (2014) Understanding nucleotide excision repair and its roles in cancer and ageing. Nat Rev Mol Cell Biol 15(7): 465-481.

Martin LP, Hamilton TC, Schilder RJ (2008) Platinum resistance: the role of DNA repair pathways. Clin Cancer Res 14(5): 1291-1295.

Mathieu V, Pirker C, Schmidt WM, Spiegl-Kreinecker S, Lotsch D, Heffeter P, Hegedus B, Grusch M, Kiss R, Berger W (2012) Aggressiveness of human melanoma xenograft models is promoted by aneuploidy-driven gene expression deregulation. Oncotarget 3(4): 399-413.

Monk BJ, Herzog TJ, Kaye SB, Krasner CN, Vermorken JB, Muggia FM, Pujade-Lauraine E, Lisyanskaya AS, Makhson AN, Rolski J, Gorbounova VA, Ghatage P, Bidzinski M, Shen K, Ngan HY, Vergote IB, Nam JH, Park YC, Lebedinsky CA, Poveda AM (2010) Trabectedin plus pegylated liposomal Doxorubicin in recurrent ovarian cancer. J Clin Oncol 28(19): 3107-3114.

Moriceau G, Rivoirard R, Mery B, Vallard A, Pacaut C, Trone JC, Espenel S, Bosacki C, Jacquin JP, Magne N (2016) Real-world outcomes of combination chemotherapy with trabectedin plus pegylated liposomal doxorubicin in patients with recurrent ovarian cancer: a single-center experience. Chemotherapy 61(3): 122-126.

Paz-Ares L, Rivera-Herreros F, Diaz-Rubio E, Garcia M, Casado E, Cubedo R, Gravalos C, Alfaro V, Gomez J, Izquierdo MA, Tabernero J (2007) Phase II study of trabectedin in pretreated patients with advanced colorectal cancer. Clin Colorectal Cancer 6(7): 522-528.

Preusser M, Spiegl-Kreinecker S, Lotsch D, Wohrer A, Schmook M, Dieckmann K, Saringer W, Marosi C, Berger W (2012) Trabectedin has promising antineoplastic activity in high-grade meningioma. Cancer 118(20): 5038-5049.

Rabik CA, Dolan ME (2007) Molecular mechanisms of resistance and toxicity associated with platinating agents. Cancer Treat Rev 33(1): 9-23.

Rosell R, Taron M, Barnadas A, Scagliotti G, Sarries C, Roig B (2003) Nucleotide excision repair pathways involved in Cisplatin resistance in non-small-cell lung cancer. Cancer Control 10(4): 297-305.

Stein A, Arnold D (2012) Oxaliplatin: a review of approved uses. Expert Opin Pharmacother 13(1): 125-137.

Stevens EV, Nishizuka S, Antony S, Reimers M, Varma S, Young L, Munson PJ, Weinstein JN, Kohn EC, Pommier Y (2008) Predicting cisplatin and trabectedin drug sensitivity in ovarian and colon cancers. Mol Cancer Ther 7(1): $10-18$.

Stevens EV, Raffeld M, Espina V, Kristensen GB, Trope CG, Kohn EC, Davidson B (2005) Expression of xeroderma pigmentosum A protein predicts improved outcome in metastatic ovarian carcinoma. Cancer 103(11): 2313-2319.

Stintzing S (2014) Management of colorectal cancer. F1000prime reports 6: 108 .

Stubbert LJ, Smith JM, McKay BC (2010) Decreased transcription-coupled nucleotide excision repair capacity is associated with increased p53and MLH1-independent apoptosis in response to cisplatin. BMC cancer 10: 207.

Sugasawa K (2009) The CUL4 enigma: culling DNA repair factors. Mol Cell 34(4): 403-404.

Takebayashi Y, Goldwasser F, Urasaki Y, Kohlhagen G, Pommier Y (2001a) Ecteinascidin 743 induces protein-linked DNA breaks in human colon carcinoma HCT116 cells and is cytotoxic independently of topoisomerase I expression. Clin Cancer Res 7(1): 185-191.

Takebayashi Y, Nakayama K, Kanzaki A, Miyashita H, Ogura O, Mori S, Mutoh M, Miyazaki K, Fukumoto M, Pommier Y (2001b) Loss of heterozygosity of nucleotide excision repair factors in sporadic ovarian, colon and lung carcinomas: implication for their roles of carcinogenesis in human solid tumors. Cancer Lett 174(2): 115-125. 
Tice RR, Agurell E, Anderson D, Burlinson B, Hartmann A, Kobayashi H, Miyamae Y, Rojas E, Ryu JC, Sasaki YF (2000) Single cell gel/comet assay: guidelines for in vitro and in vivo genetic toxicology testing. Environ Mol Mutagen 35(3): 206-221.

Torre LA, Bray F, Siegel RL, Ferlay J, Lortet-Tieulent J, Jemal A (2015) Global cancer statistics, 2012. CA Cancer J Clin 65(2): 87-108.

Vincenzi B, Napolitano A, Frezza AM, Schiavon G, Santini D, Tonini G (2010) Wide-spectrum characterization of trabectedin: biology, clinical activity and future perspectives. Pharmacogenomics 11(6): 865-878.

Weaver DA, Crawford EL, Warner KA, Elkhairi F, Khuder SA, Willey JC (2005) ABCC5, ERCC2, XPA and XRCC1 transcript abundance levels correlate with cisplatin chemoresistance in non-small cell lung cancer cell lines. Mol Cancer 4(1): 18.

Welsh C, Day R, McGurk C, Masters JR, Wood RD, Koberle B (2004) Reduced levels of XPA, ERCC1 and XPF DNA repair proteins in testis tumor cell lines. Int J Cancer 110(3): 352-361.

Wheate NJ, Walker S, Craig GE, Oun R (2010) The status of platinum anticancer drugs in the clinic and in clinical trials. Dalton Trans 39(35): 8113-8127.

Workman P, Aboagye EO, Balkwill F, Balmain A, Bruder G, Chaplin DJ, Double JA, Everitt J, Farningham DA, Glennie MJ, Kelland LR, Robinson V, Stratford IJ, Tozer GM, Watson S, Wedge SR, Eccles SA (2010) Guidelines for the welfare and use of animals in cancer research. $\mathrm{Br} J$ Cancer 102(11): 1555-1577.

Yang YL, Hung MS, Wang Y, Ni J, Mao JH, Hsieh D, Au A, Kumar A, Quigley D, Fang LT, Yeh CC, Xu Z, Jablons DM, You L (2014) Lung tumourigenesis in a conditional Cul4A transgenic mouse model. J Pathol 233(2): 113-123.

Zewail-Foote M, Li VS, Kohn H, Bearss D, Guzman M, Hurley LH (2001) The inefficiency of incisions of ecteinascidin 743-DNA adducts by the UvrABC nuclease and the unique structural feature of the DNA adducts can be used to explain the repair-dependent toxicities of this antitumor agent. Chem Biol 8(11): 1033-1049.

Zheng W, He JL, Jin LF, Lou JL, Wang BH (2005) Assessment of human DNA repair (NER) capacity with DNA repair rate (DRR) by comet assay. Biomed Environ Sci 18(2): 117-123.

This work is published under the standard license to publish agreement. After 12 months the work will become freely available and the license terms will switch to a Creative Commons AttributionNonCommercial-Share Alike 4.0 Unported License.

Supplementary Information accompanies this paper on British Journal of Cancer website (http://www.nature.com/bjc) 